
EDUCATIONAL TOOLS TO SUPPORT DAILY PRACTICE

G. R. Burmester ${ }^{1}$, J. M. Alvaro-Gracia ${ }^{2}$, N. Betteridge ${ }^{3}$, J. Calvo ${ }^{4}$, B. Combe ${ }^{5}$, P. Durez ${ }^{6}$, R. J. O. Ferreira ${ }^{7}$, B. Fautrel ${ }^{8}$, A. Iagnocco $^{9}$, C. Montecucco ${ }^{10}$, M. Ǿstergaard ${ }^{11}$, S. Ramiro ${ }^{12}$, A. Rubbert-Roth ${ }^{13}$, T. Stamm $^{14}$, Z. Szekanecz ${ }^{15}$, P. C. Taylor ${ }^{16}$, M. Van de Laar ${ }^{17} .{ }^{1}$ Charité, Berlin, Germany; ${ }^{2}$ Hospital Universitario Gregorio Marañón, Madrid, Spain; ${ }^{3}$ Neil Betteridge Associates, London, United Kingdom; ${ }^{4}$ Hospital Universitario Araba, Vitoria-Gasteiz, Spain; ${ }^{5}$ University of Montpellier, Montpellier, France; ${ }^{6}$ UCL-Saint Luc, Woluwe-Saint-Lambert, United Kingdom; ${ }^{7} \mathrm{CHUC}$, Coimbra, Portugal; ${ }^{8}$ Sorbonne University, Paris, France; ${ }^{9}$ Università di Torino, Turin, Italy; ${ }^{10}$ Policlinico San Matteo, Pavia, Italy; ${ }^{11}$ University of Copenhagen, Copenhagen, Denmark; ${ }^{12}$ LUMC, Leiden, Netherlands; ${ }^{13}$ Kantonsspital St. Gallen, St. Gallen, Switzerland; ${ }^{14}$ Medizinische Universität Wien, Vienna, Austria; ${ }^{15}$ University of Debrecen, Debrecen, Hungary; ${ }^{16}$ University of Oxford, Oxford, United Kingdom; ${ }^{17}$ MST, Enschede, Netherlands

Background: The eRA (evolving the management of RA) programme was initiated in Europe to provide practical educational tools that address unmet needs in the management of rheumatoid arthritis (RA). Several eRA tools - covering early access to care, management of comorbidities, treat-to-target strategies, and patient empowerment - are available to the rheumatology community. Through ongoing activities, the eRA Steering Committee (SC) identified a need for tools on non-pharmacological management of RA.

Objectives: To improve accessibility to eRA tools for rheumatology professionals; to review the evidence base of non-pharmacological interventions to create new eRA resources that may support management decisions.

Methods: A web platform providing information on eRA programme and tools was developed in 2019. The platform collects survey-based metrics to quantify perception of eRA and use of eRA tools in clinical practice. Platform and tools are translated to further support access and use across Europe.

To address unmet needs in non-pharmacological patient management, the eRA SC reviewed the core literature on agreed priority interventions, including physical activity, diet, patient education and self-management, psychosocial interventions, occupational therapy and orthotics, hand exercises, and hydrotherapy/balneotherapy. Available evidence for each intervention was assessed and graded according to the Oxford Centre for Evidence-based Medicine Levels of Evidence.

Results: The eRA web platform is now live in 3 countries (www.evolvingthemanagementofRA.com), hosting translated copies of the eRA tools, with additional countries launching throughout 2020.

From a review of core literature on non-pharmacological interventions, the eRA SC determined that strong evidence exists to support use of physical activity, patient education and self-management, psychosocial interventions, and occupational therapy and orthotics. Evidence was lacking or conflicting for diet and nutrition, hand exercises, and balneotherapy/hydrotherapy. A set of educational slides was produced by the eRA SC to summarise the evidence (Fig. 1) and provide top-line guidance on use of interventions in practice that should engage relevant members of the multi-disciplinary team. These slides are available through eRA dissemination activities.

Conclusion: The eRA programme content is now freely available to health care professionals in several countries on a web platform, supported by translations of the eRA tools. An additional slide set on non-pharmacological management serves to further increase the practical guidance of this programme's educational offering.

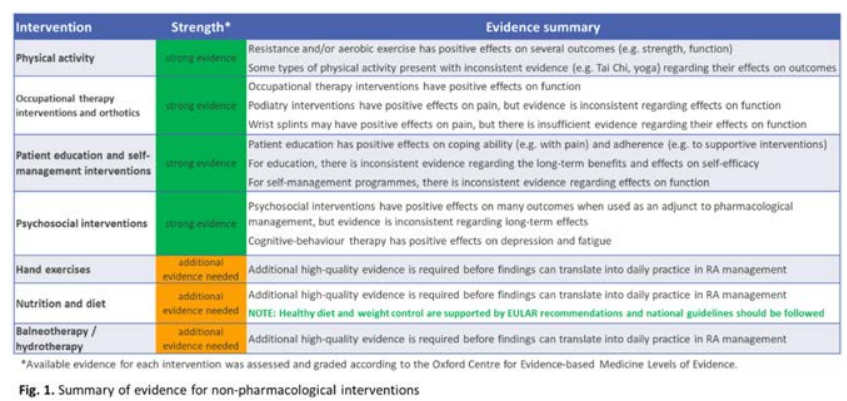

Acknowledgments: The eRA programme is funded by Sanofi Genzyme. Programme direction and content creation are driven by an independent Steering Committee

Disclosure of Interests: Gerd Rüdiger Burmester Consultant of: AbbVie Inc, Eli Lilly, Gilead, Janssen, Merck, Roche, Pfizer, and UCB Pharma, Speakers bureau: AbbVie Inc, Eli Lilly, Gilead, Janssen, Merck, Roche, Pfizer, and UCB Pharma, Jose-Maria Alvaro-Gracia Grant/research support from: Abbvie, ElliLilly, MSD, Novartis, Pfizer, Consultant of: Abbvie, BMS, Janssen-Cilag, Elli-Lilly,
MSD, Novartis, Pfizer, Sanofi, Tigenix, Roche, UCB, Paid instructor for: Elli-Lilly, Pfizer, Roche, Speakers bureau: Abbvie, BMS, Janssen-Cilag, Elli-Lilly, Gedeon Richter, MSD, Novartis, Pfizer, Sanofi, Tigenix, Roche, UCB, Neil Betteridge Consultant of: Amgen, Eli Lilly and Company, Grunenthal, GSK, Sanofi Genzyme, Jaime Calvo Grant/research support from: Lilly, UCB, Consultant of: Abbvie, Jansen, Celgene, Bernard Combe Grant/research support from: Novartis, Pfizer, Roche-Chugai, Consultant of: AbbVie; Gilead Sciences, Inc.; Janssen; Eli Lilly and Company; Pfizer; Roche-Chugai; Sanofi, Speakers bureau: Bristol-Myers Squibb; Gilead Sciences, Inc.; Eli Lilly and Company; Merck Sharp \& Dohme; Pfizer; Roche-Chugai; UCB, Patrick Durez Speakers bureau: AbbVie, Bristol-Myers Squibb, Celltrion, Eli Lilly, Pfizer, Sanofi, Ricardo J. O. Ferreira Grant/ research support from: Abbvie, Consultant of: Sanofi Genzyme, Amgen, MSD, Paid instructor for: UCB, Bruno Fautrel Grant/research support from: AbbVie, Lilly, MSD, Pfizer, Consultant of: AbbVie, Biogen, BMS, Boehringer Ingelheim, Celgene, Lilly, Janssen, Medac MSD France, Nordic Pharma, Novartis, Pfizer, Roche, Sanofi Aventis, SOBI and UCB, Annamaria lagnocco Grant/research support from: Abbvie, MSD and Alfasigma, Consultant of: AbbVie, Abiogen, Alfasigma, Biogen, BMS, Celgene, Eli-Lilly, Janssen, MSD, Novartis, Sanofi and Sanofi Genzyme, Speakers bureau: AbbVie, Alfasigma, BMS, Eli-Lilly, Janssen, MSD, Novartis, Sanofi, Carlomaurizio Montecucco: None declared, Mikkel Ǿstergaard Grant/research support from: AbbVie, Bristol-Myers Squibb, Celgene, Merck, and Novartis, Consultant of: AbbVie, Bristol-Myers Squibb, Boehringer Ingelheim, Celgene, Eli Lilly, Hospira, Janssen, Merck, Novartis, Novo Nordisk, Orion, Pfizer, Regeneron, Roche, Sandoz, Sanofi, and UCB, Speakers bureau: AbbVie, Bristol-Myers Squibb, Boehringer Ingelheim, Celgene, Eli Lilly, Hospira, Janssen, Merck, Novartis, Novo Nordisk, Orion, Pfizer, Regeneron, Roche, Sandoz, Sanofi, and UCB, Sofia Ramiro Grant/research support from: MSD, Consultant of: Abbvie, Lilly, Novartis, Sanofi Genzyme, Speakers bureau: Lilly, MSD, Novartis, Andrea Rubbert-Roth Consultant of: Abbvie, BMS, Chugai, Pfizer, Roche, Janssen, Lilly, Sanofi, Amgen, Novartis, Tanja Stamm Grant/research support from: AbbVie, Roche, Consultant of: AbbVie, Sanofi Genzyme, Speakers bureau: AbbVie, Roche, Sanofi, Zoltán Szekanecz Grant/research support from: Pfizer, UCB, Consultant of: Sanofi, MSD, Abbvie, Pfizer, Roche, Novertis, Lilly, Gedeon Richter, Amgen, Peter C. Taylor Grant/research support from: Celgene, Eli Lilly and Company, Galapagos, and Gilead, Consultant of: AbbVie, Biogen, Eli Lilly and Company, Fresenius, Galapagos, Gilead, GlaxoSmithKline, Janssen, Nordic Pharma, Pfizer Roche, and UCB, Mart van de Laar Consultant of: Sanofi Genzyme, Speakers bureau: Sanofi Genzyme DOI: 10.1136/annrheumdis-2020-eular.1219

\section{THU0580 EULAR TASK FORCE ON GENDER EQUITY IN ACADEMIC RHEUMATOLOGY: PRELIMINARY SURVEY FINDINGS}

P. V. Ovseiko ${ }^{1}$, L. Gossec ${ }^{1}$, L. Andreoli ${ }^{1}$, U. Kiltz ${ }^{1}$, L. Van Mens ${ }^{1}$, N. Hassan ${ }^{1}$, M. Van der Leeden ${ }^{1}$, H. J. Siddle ${ }^{1}$, A. Alunno ${ }^{1}$, I. Mcinnes ${ }^{1}$, N. Damjanov ${ }^{1}$, F. Apparailly ${ }^{1}$, C. Ospelt ${ }^{1}$, I. Van der Horst-Bruinsma ${ }^{1}$, E. Nikiphorou ${ }^{1}$,

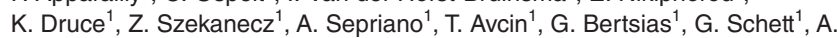
M. Keenan ${ }^{1}$, L. C. Coates ${ }^{1}$ on behalf of EULAR Task Force on Gender Equity in Academic Rheumatology. ${ }^{1}$ EULAR Task Force on Gender Equity in Academic Rheumatology, Zürich, Switzerland

Background: Women represent an increasing proportion of the overall rheumatology workforce, but are underrepresented in academic rheumatology, especially in leadership roles [1]

Objectives: The EULAR Task Force on Gender Equity in Academic Rheumatology has been convened to establish the extent of the unmet need for support of female rheumatologists, health professionals and non-clinical scientists in academic rheumatology and develop a framework to address this through EULAR and EMEUNET.

Methods: To investigate gender equity in academic rheumatology, an anonymous web-based survey was targeted at the membership of EULAR and Emerging EULAR Network (EMEUNET) and their wider networks. The survey was developed based on a narrative literature review [1], best practice from The Association of Women in Rheumatology, a survey of task force members and face-to-face task force discussions. Personal experiences were explored and 24 potential interventions to aid career advancement were ranked. Statistics were descriptive with significance testing for male/female responses compared using chi-squared/t-tests. The level of significance was set at $p<0.001$.

Results: A total of 301 respondents from 24 countries fully completed the survey. By profession, $290(86.4 \%)$ were rheumatologists, $19(6.3 \%)$ health professionals, and $22(7.3 \%)$ non-clinical scientists. By gender, $217(72.1 \%)$ were women, $83(27.6 \%)$ men, and $1(0.3 \%)$ third gender. By age, $203(67.5 \%)$ were 40 or under. By ethnicity, $30(10.0 \%)$ identified themselves as ethnic minority. A high proportion of respondents reported having experienced gender discrimination (47.2\% total: $58.1 \%$ for women and $18.1 \%$ for men) and sexual harassment (26.2\%: $31.8 \%$ and $10.8 \%$ respectively) (Figure 1 ). Chisquared tests on the numbers on which these proportions were based showed 
statistically significant differences between women and men in having experienced gender discrimination $(X 2=36.959(\mathrm{df}=1), \mathrm{p}<0.001)$ and sexual harassment $(X 2=12.633(d f=1), p<0.001)$. The highest-ranked interventions for career advancement regardless of respondents' gender included: leadership skills training; speaking/presentation/communication skills training; information on training/career pathways; effective career planning training; support on grant writing applications; and high-impact scientific writing master-classes (Figure 2). Only 8 of 24 proposed interventions showed a significantly higher ranking $(p<0.001)$ by female respondents and these typically related to promotion of female role models and gender-balance in committees, editorial boards and research funding (Figure 2).

Responses to the question "Please tell us if you have personally experienced in your professional career any gender discrimination or sexual harassment"

Gender discrimination

(unequal or disadvantageous treatment)

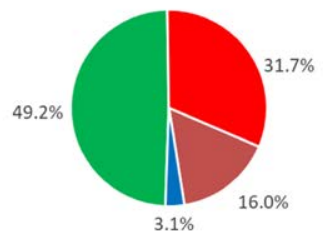

Sexual harassment unwanted behaviour of a sexual nature)

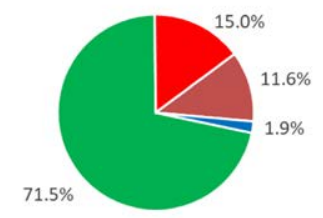

- No, never - Yes, within the last five years - Yes, over five years ago - Don't know/not applicable

Figure 1. Perceived gender discrimination and sexual harassment, 301 responses

Responses to the question "Please indicate how strongly you agree or disagree that the following interventions would be helpful for your career advancement" on a five-point scale from "strongly disagree" $=1$ to "strongly agree" $=5$

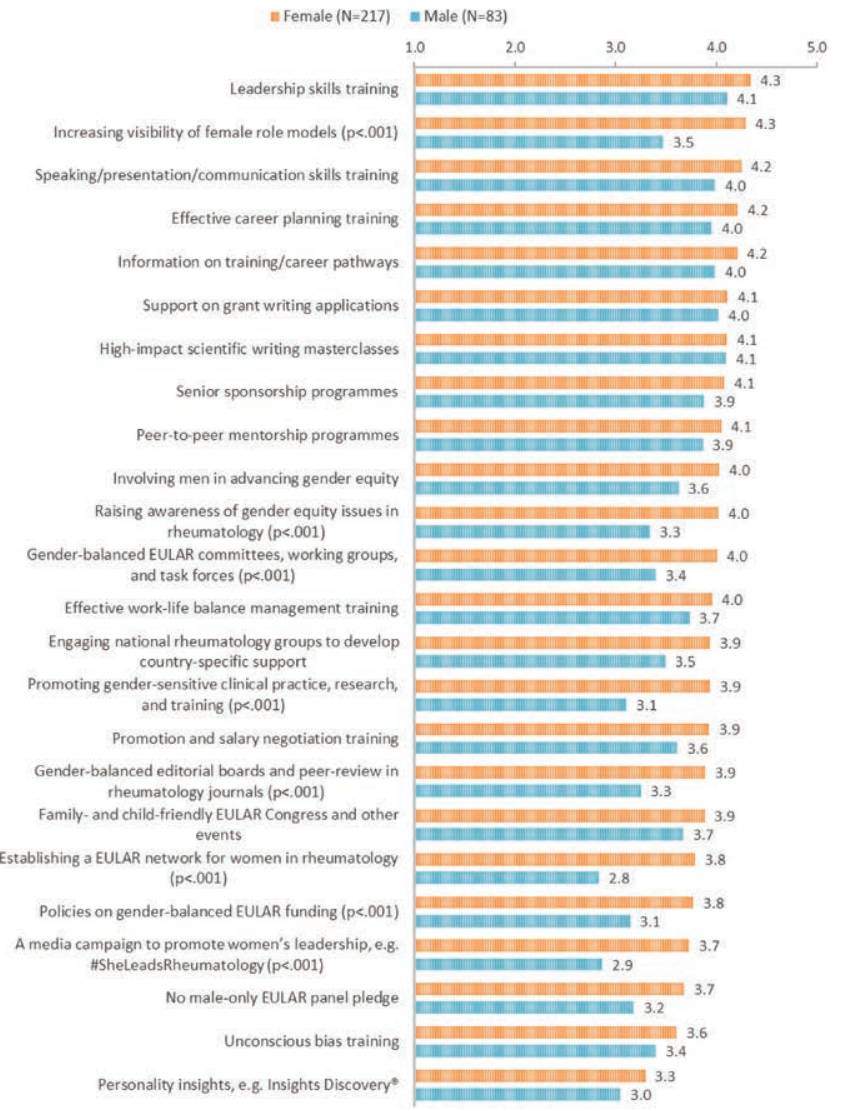

Figure 2. Mean perceived utility of potential interventions for career advancement by gender and statistically significant gender differences $(p<.001), 300$ responses

Conclusion: The results of the survey will inform the development of task force policy proposals for interventions to support career advancement among EULAR and EMEUNET members. The identified interventions have potential to support career advancement of all rheumatologists, health professionals and non-clinical scientists regardless of gender.

\section{References:}

[1] Andreoli L, Ovseiko PV, Hassan N, Kiltz U, van Mens L, Gossec L, et al. Gender equity in clinical practice, research and training: Where do we stand in rheumatology? Joint, Bone, Spine: Revue du Rhumatisme. 2019;86(6):669-672.

Acknowledgments: We gratefully acknowledge the rheumatologists, health professionals and non-clinical scientists who responded to the survey.

Disclosure of Interests: Pavel V Ovseiko: None declared, Laure Gossec Grant/research support from: Lilly, Mylan, Pfizer, Sandoz, Consultant of: AbbVie, Amgen, Biogen, Celgene, Janssen, Lilly, Novartis, Pfizer, Sandoz, SanofiAventis, UCB, Laura Andreoli: None declared, Uta Kiltz Grant/research support from: AbbVie, Amgen, Biogen, Novartis, Pfizer, Consultant of: AbbVie, Biocad Eli Lilly and Company, Grünenthal, Janssen, Novartis, Pfizer, UCB, Speakers bureau: AbbVie, MSD, Novartis, Pfizer, Roche, UCB, Leonieke van Mens: None declared, Neelam Hassan: None declared, Marike van der Leeden: None declared, Heidi J Siddle: None declared, Alessia Alunno: None declared, Iain Mclnnes Grant/research support from: Bristol-Myers Squibb, Celgene, Eli Lilly and Company, Janssen, and UCB, Consultant of: AbbVie, Bristol-Myers Squibb Celgene, Eli Lilly and Company, Gilead, Janssen, Novartis, Pfizer, and UCB Nemanja Damjanov Grant/research support from: from AbbVie, Pfizer, and Roche, Consultant of: AbbVie, Gedeon Richter, Merck, Novartis, Pfizer, and Roche, Speakers bureau: AbbVie, Gedeon Richter, Merck, Novartis, Pfizer, and Roche, Florence Apparailly: None declared, Caroline Ospelt Consultant of: Consultancy fees from Gilead Sciences., Irene van der Horst-Bruinsma Grant/ research support from: AbbVie, Novartis, Eli Lilly, Bristol-Myers Squibb, MSD Pfizer, UCB Pharma, Consultant of: AbbVie, Novartis, Eli Lilly, Bristol-Myers Squibb, MSD, Pfizer, UCB Pharma, Elena Nikiphorou: None declared, Katie Druce Speakers bureau: Pfizer and Lilly, Zoltán Szekanecz Grant/research support from: Pfizer, UCB, Consultant of: Sanofi, MSD, Abbvie, Pfizer, Roche Novertis, Lilly, Gedeon Richter, Amgen, Alexandre Sepriano: None declared, Tadej Avcin: None declared, George Bertsias Grant/research support from: GSK, Consultant of: Novartis, Georg Schett Speakers bureau: AbbVie, BMS Celgene, Janssen, Eli Lilly, Novartis, Roche and UCB, Anne Maree Keenan: None declared, Laura C Coates: None declared

DOI: 10.1136/annrheumdis-2020-eular.3384

\section{THU0581 \\ USE OF EHEALTH BY PATIENTS WITH RHEUMATOID ARTHRITIS: AN OBSERVATIONAL, CROSS SECTIONAL, MULTICENTER STUDY}

M. Magnol ${ }^{1}$, E. Berard ${ }^{2}$, C. Rempenault ${ }^{3}$, B. Castagne ${ }^{4}$, M. Pugibet $^{5}$, C. Lukas $^{3}$, A. Tournadre ${ }^{4}$, P. Vergne-Salle ${ }^{5}$, T. Barnetche ${ }^{2}$, M. E. Truchetet ${ }^{2}$, A. RuyssenWitrand $1 .{ }^{1} \mathrm{CHU}$ Toulouse Pierre Paul Riquet, Rhumatology, Toulouse, France; ${ }^{2} \mathrm{CHU}$ Bordeaux Pellegrin, Rhumatology, Bordeaux, France; ${ }^{3} \mathrm{CHU}$ Monptellier Lapeyronie, Rhumatology, Montpellier, France; ${ }^{4} \mathrm{CHU}$ Clermont Ferrand, Rhumatology, Clermont Ferrand, France; ${ }^{5} \mathrm{CHU}$ Limoges, Rhumatology, Limoges, France

Background: The use of eHealth tools (internet, mobile applications, connected devices) in chronic diseases and in the field of rheumatoid arthritis (RA) is growing (1). eHealth may improve the overall care of patients suffering from chronic diseases $(2,3)$.

Objectives: The main objective of this study was to describe the use of eHealth by RA patients in France. The secondary objectives were to identify differences in demographic and disease characteristics between patients using eHealth tools or not. We also assessed patients' expectations about digital devices.

Methods: We conducted a cross-sectional, multicenter study. Patients with RA according to the ACR / EULAR 2010 criteria were recruited in 5 university hospitals (Bordeaux, Clermont-Ferrand, Limoges, Montpellier and Toulouse). Patients completed an anonymous self-questionnaire including demographic data, assessment about the use of eHealth (access, support, frequency of use, type of use, reason for use). The treating rheumatologist of the patient filled in an independent medical questionnaire collecting the disease characteristics, the activity of RA and the treatments. Data were collected from December 2018 to July 2019.

Results: The questionnaires were completed by 575 patients, with an average age of $62 \pm 13$ years, $78 \%$ of whom were women. $473(82 \%)$ patients had access to eHealth through a computer $(n=402,86 \%)$, a tablet $(n=188,40 \%)$ and/or a smartphone ( $n=221,47 \%$ ). Among them, 36\% (170/473) used internet for health in general and 29\% (134/473) specifically for RA. Regarding the use of eHealth for RA, all patients used it to learn about their disease and $66 \%(89 / 134)$ as a tool to help monitoring RA. Most of them $(n=87 / 125,70 \%)$ had a paper medical record, $24 / 125$ patients (19\%) used a digital tool (spreadsheet $n=10,8 \%$ and $/$ or mobile application $n=9,7 \%$ and / or website $n=5,4 \%$ ) and $31 / 125$ patients 